\title{
Soil phosphorus fractions vary with harvest intensity and vegetation control at two contrasting Douglas-fir sites in the Pacific northwest
}

\author{
Daniel G. DeBruler ${ }^{\mathrm{a}}$, Stephen H. Schoenholtz ${ }^{\mathrm{b}}$, Robert A. Slesak ${ }^{\mathrm{c}, *}$, Brian D. Strahm ${ }^{\mathrm{a}}$, \\ Timothy B. Harrington ${ }^{\mathrm{d}}$ \\ ${ }^{a}$ Virginia Tech, Department of Forest Resources and Environmental Conservation, Blacksburg, VA 24061, United States \\ ${ }^{\mathrm{b}}$ Virginia Tech, Virginia Water Resources Research Center, Blacksburg, VA 24061, United States \\ ${ }^{\mathrm{c}}$ University of Minnesota, Department of Forest Resources, St. Paul, MN 55108, United States \\ ${ }^{\mathrm{d}}$ USDA Forest Service, Pacific Northwest Research Station, Olympia, WA 98512-9193, United States
}

\section{A R T I C L E I N F O}

Handling Editor: Jan Willem Van Groenigen

\section{Keywords:}

Site-specific response

Scotch broom

Long-term soil productivity

Phosphorus

Selective dissolution extraction

\begin{abstract}
A B S T R A C T
Effects of intensive forest management on soil phosphorus (P) are unclear and may impact long-term site productivity. We assessed changes in P availability over 10 years associated with harvest intensity (bole-only vs. whole-tree harvest) and vegetation control treatments (initial vegetation control (IVC) vs. five years of annual vegetation control $(A V C)$ ) using a $P$ fractionation procedure. Fractions were characterized at $0-15,15-30$, and 30-60 cm soil depths in two coast Douglas-fir (Pseudotsuga menziesii (Mirb.) Franco var. menziesii) plantations with strongly contrasting soil properties near Matlock, WA (young soils formed in glacial outwash) and Molalla, OR (relatively old soils formed in igneous residuum and exhibiting andic properties). Al and Fe concentrations associated with short-range order minerals were greater at Molalla than Matlock and generally decreased with depth at both sites. We observed decreases in most total-P and P-fraction concentrations across the three soil depths at the Molalla site. Effects were less pronounced and generally inconsistent at the Matlock site. Decreases in total P and P fraction concentrations were greatest in the AVC treatments at Matlock, but opposite trends were observed at Molalla where decreases were greatest with IVC. There was no difference between harvest treatments on the change in $\mathrm{P}$ fractions in most instances, with the exception of the $30-60 \mathrm{~cm}$ depth at Matlock where concentrations of some $\mathrm{P}$ fractions were maintained or increased with bole-only harvesting. Ten-year responses indicate harvest intensity has limited effects on long-term productivity associated with soil $\mathrm{P}$ because of the large size of the soil P pools and the relatively small changes in soil P that occurred with treatment. Decreases in $\mathrm{P}$ concentrations with AVC at Matlock and IVC at Molalla were larger than the other treatments and highlight the important role of vegetation in P dynamics following harvesting at these sites.
\end{abstract}

\section{Introduction}

Intensive forest management is characterized by increased fiber removals at shorter rotations coupled with increased cultural inputs such as herbicide application for vegetation control. This type of management is very effective at increasing fiber production (Adams et al., 2005), but also increases the risk of reduced productivity over time because of impacts to soil properties that control resource supply for plant growth (Powers et al., 1990). Intensive management is generally associated with a net increase in nutrient removal from a site relative to less intensive practices, and it influences processes that control nutrient loss and retention immediately following harvest, such as leaching, erosion, and growth of competing vegetation (Vitousek and
Matson, 1985; Smethurst and Nambiar, 1995). These direct and indirect effects on nutrient pools have the potential to reduce soil resources such as available phosphorus (P).

The USDA Forest Service Long-term Soil Productivity (LTSP) study was launched in 1989 to elucidate effects of intensive forest management on long-term soil productivity in North America (Powers et al., 2005). Research conducted within the North American LTSP study aimed to answer questions that arise from potential changes in soil productivity and concern over observed or hypothesized management effects on soil quality (Boyle and Ek, 1972; Powers et al., 1990). In the U.S. Pacific Northwest (PNW), LTSP research has focused mainly on soil organic carbon (C) (Powers et al., 1990) and nitrogen (N) limitation (Chappell et al., 1991). Soil $\mathrm{P}$ has been less studied despite

\footnotetext{
* Corresponding author at: 115 Green Hall, 1530 Cleveland Avenue N., St. Paul, MN 55108, United States.

E-mail address: raslesak@umn.edu (R.A. Slesak).
} 
acknowledgement of potential $\mathrm{N}-\mathrm{P}$ co-limitation and other nutrient interactions (Spears et al., 2001; Vitousek et al., 2010). Additionally, there have been few studies in this region that measured changes in soil $\mathrm{P}$ over extended periods of time in response to intensive forest management.

Sequential P fractionation was first developed as a method of observing changes in soil $\mathrm{P}$ fractions caused by cultivation of field crops (Hedley et al., 1982). More recently it has been used in research to investigate the role of $\mathrm{P}$ biogeochemistry in forested terrestrial ecosystems (Giardina et al., 1995; Compton and Cole, 1998; Spears et al., 2001; Ilg et al., 2009; Celi et al., 2013), which differ from field crops in their longer rotation lengths, management regimes, and perennial plant communities. Fractionation has been used to separate labile, moderately-labile, and recalcitrant forms of $\mathrm{P}$ and to differentiate inorganic and organic forms within these classes. There have been many modifications (e.g., addition of different extraction steps, varying concentration of extractants, and use of physical extraction techniques such as sonic baths) of fractionation procedures with new technology and insight, but the concept of separating P fractions based on chemical susceptibility to different extracting solutions remains consistent (Robertson et al., 1999). Although these extractions provide only an approximation for theoretical pools, their usefulness in exploring questions pertaining to development and evolution of $\mathrm{P}$ pools over time is well-supported (Walker and Syers, 1976; Crews et al., 1995; Schlesinger et al., 1998).

In the PNW, soil $\mathrm{P}$ fractionation has been used to compare availableand other $\mathrm{P}$ fractions in association with different tree species and how composition changes available-P fractions in stands with intermixed species including Douglas-fir (Giardina et al., 1995; Compton and Cole, 1998; Spears et al., 2000). Vegetation in general has a large influence on $\mathrm{P}$ availability and cycling through conversion of inorganic $\mathrm{P}$ into less-available organic and occluded forms (Walker and Syers, 1976), and potentially greater influence when the vegetation is capable of fixing atmospheric N (Houlton et al., 2008). For example, Compton and Cole (1998) demonstrated that plant-available P fractions were generally increased in the presence of red alder (Alnus rubra Bong.), and Giardina et al. (1995) also showed that available inorganic P was increased in the presence of alder. Such an effect may be dependent on soil or other site factors (e.g. rainfall, microbial communities, and invasive plant growth) that influence the forms and magnitude of available soil P or total soil N (Holub et al., 2013; Slesak et al., 2016a).

The relationship between $\mathrm{N}$-fixing plant species and available-P fractions becomes relevant in relation to vegetation control practices, which may alter the composition of plants that stimulate rhizosphere interactions and phosphatase activity (Caldwell, 2006). Plant uptake of available $\mathrm{P}$ may also change the equilibrium of labile $\mathrm{P}$, with the nonoccluded organic fractions increasing phosphatase activity and decreasing the reserve fractions of P (Sharpley and Smith, 1985). Sequential $\mathrm{P}$ fractionation could provide insight on $\mathrm{P}$ biogeochemical processes as affected by harvesting and vegetation control treatments and how those treatments and related effects on vegetation uptake of $P$ affect different $\mathrm{P}$ fractions. Inference generated by additional knowledge of $\mathrm{P}$ dynamics will yield greater understanding of these treatments and their effect on $\mathrm{P}$ pools.

The objectives of this study were to determine if harvest-intensity treatments and vegetation control treatments affected soil $\mathrm{P}$ fractions over a ten-year period since harvest and treatment, how the responses may differ between sites with distinctly different soils, and whether or not effects on soil $\mathrm{P}$ were associated with foliar P nutrition. We measured concentrations of five $\mathrm{P}$ fractions from two contrasting sites supporting Douglas-fir plantations in the PNW, analyzed foliage P from Douglas-fir trees on the same plots, and additionally conducted selective dissolution extractions to further characterize soils and provide context to how mineralogy influences responses to changes in phosphorus fractions, were performed. We expected that more intense
Table 1

Site characteristics and soil properties from pre-treatment mineral soil samples collected in 2003 with soil nutrient content from a depth of $0-60 \mathrm{~cm}$ at study sites near Matlock, WA and Molalla, OR.

\begin{tabular}{|c|c|c|}
\hline Variable & Matlock & Molalla \\
\hline Latitude & $47.206^{\circ} \mathrm{N}$ & $45.196^{\circ} \mathrm{N}$ \\
\hline Longitude & $123.442^{\circ} \mathrm{W}$ & $122.285^{\circ} \mathrm{W}$ \\
\hline Elevation (m) & 35 & 549 \\
\hline Mean annual precipitation $(\mathrm{cm})^{\mathrm{a}}$ & 240 & 160 \\
\hline Mean annual temperature $\left({ }^{\circ} \mathrm{C}\right)^{\mathrm{a}}$ & 10.7 & 11.2 \\
\hline Stand age at harvest $(\mathrm{yr})^{\mathrm{b}}$ & 45 & 56 \\
\hline Basal area at harvest $\left(\mathrm{m}^{2} \mathrm{ha}^{-1}\right)^{\mathrm{b}}$ & 35 & 46 \\
\hline Parent material & Glacial outwash & Igneous residuum \\
\hline Approximate site age (yr) & 10,000 & 4.1 million \\
\hline Particle-size distribution (\% sand/silt/clay) ${ }^{\mathrm{d}}$ & $65 / 14 / 21$ & $37 / 34 / 29$ \\
\hline Bulk density $\left(\mathrm{Mg} \mathrm{m}^{-3}\right)^{\mathrm{c}}$ & $1.45(0.05)^{\mathrm{e}}$ & $0.98(0.02)$ \\
\hline Coarse fragments by mass $(\%)^{c}$ & $67.6(1.3)$ & $37.7(2.2)$ \\
\hline Water holding capacity $(\mathrm{mm})^{\mathrm{c}}$ & 55 & 142 \\
\hline \multicolumn{3}{|l|}{ Soil $\mathrm{pH}^{\mathrm{c}}$} \\
\hline $0-15 \mathrm{~cm}$ & $5.08(0.06)$ & $5.41(0.03)$ \\
\hline $15-30 \mathrm{~cm}$ & $5.28(0.05)$ & $5.47(0.04)$ \\
\hline $30-60 \mathrm{~cm}$ & $5.42(0.07)$ & $5.48(0.05)$ \\
\hline Total soil C $\left(\mathrm{Mg} \mathrm{ha}^{-1}\right)^{\mathrm{c}}$ & $92.4(5.8)$ & $169.5(12.0)$ \\
\hline Total soil $\mathrm{N}\left(\mathrm{kg} \mathrm{ha}^{-1}\right)^{\mathrm{c}}$ & $3300(150)$ & $7220(410)$ \\
\hline Total soil $\mathrm{P}\left(\mathrm{kg} \mathrm{ha}^{-1}\right)$ & $3290(150)$ & $2970(170)$ \\
\hline Exchangeable Ca $\left(\mathrm{kg} \mathrm{ha}^{-1}\right)^{\mathrm{c}}$ & $420(43)$ & $5050(683)$ \\
\hline Exchangeable $\mathrm{Mg}\left(\mathrm{kg} \mathrm{ha}^{-1}\right)^{\mathrm{c}}$ & $35(2)$ & $604(97)$ \\
\hline Exchangeable $\mathrm{K}\left(\mathrm{kg} \mathrm{ha}^{-1}\right)^{\mathrm{c}}$ & $124(5)$ & $1430(152)$ \\
\hline
\end{tabular}

${ }^{\text {a }}$ From Slesak et al., 2016b.

b From Harrington and Schoenholtz, 2010.

c From Slesak et al., 2011.

d Estimated for a $1.25 \mathrm{~m}$ profile based on pressure plate analyses by the Central Analytical Laboratory, Oregon State University, Corvallis, OR.

e Standard error of mean, $\mathrm{n}=16$.

management practices, especially when applied in tandem (e.g., greater harvest intensity and more prolonged vegetation control), would have greater reductions in $\mathrm{P}$ fractions compared to less intensive practices. The ten-year time span of observation in this study is aimed to yield more applicable assessments of treatment effects on long-term soil productivity in early rotation sites managed for forest production.

\section{Methods}

\subsection{Site descriptions}

The two sites used in this study, Matlock and Molalla, are affiliates of the North American LTSP network (Powers et al., 2005). These sites were established in 2003 to study effects of biomass removal and vegetation control on nutrient cycling, Douglas-fir growth, competing vegetation, and soil properties. The sites have a climate with cool, wet winters and warm, dry summers. Mean annual precipitation is $240 \mathrm{~cm}$ at Matlock and $160 \mathrm{~cm}$ at Molalla (Table 1; Slesak et al., 2016b).

The Matlock site is located on the Olympic Peninsula in WA with soils classified as sandy-skeletal, mixed, mesic Dystric Xerorthents on $0-3 \%$ slopes forming in glacial outwash (Soil Survey Staff, 2019). The Molalla site is located in the western foothills of the Cascade Range in OR with soils classified as fine-loamy, isotic, mesic Andic Humudepts on $2-40 \%$ slopes forming in residuum derived from hard extrusive igneous rock and soft tuff mixed with volcanic ash in the upper part (Soil Survey Staff, 2019). Soil properties of each site contrasted strongly (Table 1). Soils at Matlock are much younger, and more coarsely textured with higher coarse-fragment content, low water-holding capacity, and lower nutrient contents relative to Molalla (Devine et al., 2011). More information on the sites and soil responses at them can be found in Slesak et al. (2011, 2016a, 2016b). 
Table 2

Terminology of phosphorus fractions in the sequential extraction (adapted from Cross and Schlesinger, 1995).

\begin{tabular}{|c|c|c|}
\hline P-fraction & Description & Extractant \\
\hline Labile P & $\begin{array}{l}\text { Readily plant-available inorganic } \mathrm{P} \text { and organic } \mathrm{P} \text { that is easily hydrolysable and contributes to } \\
\text { plant-available } \mathrm{P}\end{array}$ & $0.5 \mathrm{M} \mathrm{NaHCO} 3$ \\
\hline Moderately labile P & $\mathrm{P}$ associated with Fe- and $\mathrm{Al}$ - phosphates and organic $\mathrm{P}$ contributing to plant-available $\mathrm{P}$ & $0.1 \mathrm{M} \mathrm{NaOH}$ \\
\hline Moderately recalcitrant $\mathrm{P}$ & $\begin{array}{l}\text { P held at internal surfaces of soil aggregates and organic } P \text { that is more strongly sorbed to soil } \\
\text { surfaces }\end{array}$ & $0.1 \mathrm{M} \mathrm{NaOH}$ with sonication \\
\hline Ca-bound P & Unavailable inorganic $\mathrm{P}$ that is Ca-bound in primary minerals or precipitated Ca-phosphate & $1.0 \mathrm{M} \mathrm{HCl}$ \\
\hline Residual P & Non-extractable $\mathrm{P}$, and $\mathrm{P}$ that is considered to be slow turn-over & $\begin{array}{l}\text { Concentrated sulfuric acid and Cu-catalyzed } \\
\text { digestion }\end{array}$ \\
\hline
\end{tabular}

\subsection{Design and treatment application}

Sites were clear-cut in spring 2003, with trees de-limbed at the stump and merchantable portions removed using mechanized ground equipment along paths designed to minimize soil disturbance (Harrington and Schoenholtz, 2010). After harvest, both sites were planted with Douglas-fir seedlings in February of 2004 at $3 \times 3 \mathrm{~m}$ spacing (Harrington and Schoenholtz, 2010), and a $2 \times 2$ randomized complete block design with four replicates was installed. Each of the 16 treatment plots was $50 \times 60 \mathrm{~m}(0.3 \mathrm{ha})$ in size, which included a $10-\mathrm{m}$ perimeter buffer around a 30- $\times 40-\mathrm{m}$ measurement plot.

Two factors, harvest intensity and vegetation control with herbicides were tested. Harvest-intensity treatments included bole-only (BO) harvesting, where only the merchantable logs $(\geq 12.7 \mathrm{~cm}$ in diameter) were removed and whole-tree (WT) harvesting, where merchantable logs and most of the logging debris (tree tops and branches $\geq 5.1 \mathrm{~cm}$ in diameter) were removed. Within these treatments, logging-debris mass was similar between sites. Estimated mass of logging debris retained (mean \pm standard error) was $22.5 \pm 3.0$ and $13.5 \pm 3.0 \mathrm{Mg} \mathrm{ha}^{-1}$ in the BO and WT harvests, respectively, at Matlock, and $24.0 \pm 2.8$ and $13.9 \pm 2.8 \mathrm{Mg} \mathrm{ha}^{-1}$ in the BO and WT harvests, respectively, at Molalla (Harrington and Schoenholtz, 2010). Estimated P retained in logging debris was $6.3(\sim 30 \%$ of preharvest Douglas-fir aboveground $\mathrm{P})$ and $4.6(\sim 20 \%$ of preharvest Douglas-fir aboveground $\mathrm{P}) \mathrm{kg} \mathrm{ha}^{-1}$ in the BO and WT harvests, respectively, at Matlock, and $8.9(\sim 30 \%$ of preharvest Douglas-fir aboveground P) and $4.0(\sim 15 \%$ of preharvest Douglas-fir aboveground P) in the BO and WT harvests, respectively, at Molalla (T. Harrington, unpublished data).

The two levels of vegetation control included initial vegetation control (IVC) for the first year only or annual vegetation control (AVC) during the first five years (Harrington and Schoenholtz, 2010). Plant communities within the study sites were characterized five years after treatment application (Peter and Harrington, 2012). At Matlock, the three most abundant species and their areal percent cover in IVC plots were oxeye daisy (Leucanthemum vulgare Lam.; $28 \%$ cover), hairy cat's ear (Hypochaeris radicata L.; 27\% cover), and Douglas-fir (8\% cover). Scotch broom (Cytisus scoparius (L.) Link.) invaded at Matlock and three additional weed control spray treatments specifically targeting the species were used in years 1,4 , and 5 in all plots and were successful in eliminating much of the Scotch broom (Peter and Harrington, 2012). By the tenth year of the study (2013), the Scotch broom had reinvaded Matlock, and its cover differed significantly between the BO (3\%) and WT (10\%) treatments, but not between the AVC (5\%) and IVC (7\%) treatments (D. Peter and T. Harrington, unpublished data). At Molalla, the most abundant species in IVC plots were California blackberry (Rubus ursinus Cham. \& Schltdl.; 55\% cover), velvet grass (Holcus lanatus L.; $27 \%$ cover), and Douglas-fir ( $12 \%$ cover) (Peter and Harrington, 2012). Plots with AVC had similar species but with decreased canopy covers except for the crop tree, Douglas-fir, which had covers of 15.2 and $15.9 \%$ for Matlock and Molalla, respectively. By year 10, Douglas-fir cover differed between IVC and AVC as follows: 26.3 vs. $58.8 \%$ at Matlock and 67.1 and $80.7 \%$ at Molalla, respectively (Slesak et al., 2016b).

\subsection{Soil sampling}

Soil sampling was conducted pre-harvest in winter 2003 and again ten years following harvest in spring 2013. Soils were sampled from depths of 0-15, 15-30, and 30-60 cm at five points per plot with bucket augers. Samples were collected from each of the four corners of each plot within the plot area bounded by Douglas-fir trees and one from the central point of each plot. Samples were then composited in the field by depth. Pre-harvest (2003) and ten-year (2013) soil samples were airdried $\left(35^{\circ} \mathrm{C}\right)$ and returned to the laboratory where the soil was sieved to pass a $2-\mathrm{mm}$ mesh and archived.

\subsection{Foliage sampling and analysis}

Current-year shoots were collected from the second-whorl of Douglas-fir trees in fall 2013 for estimation of foliar nutrient concentrations. Shoots were ground in a Wiley mill to pass a $1 \mathrm{~mm}$ sieve, and then dried at $65{ }^{\circ} \mathrm{C}$ to constant mass. Samples were submitted to Central Analytical Laboratory, Oregon State University, Corvallis, OR and analyzed for $\mathrm{N}$ with dry combustion (LECO Corporation, CNS 2000 Elemental Analyzer) and for P with ICP-OES (PerkinElmer Inc., Optima $2100 \mathrm{DV}$ ) after dry-ashing in a porcelain crucible and subsequent dissolution in $1.0 \mathrm{M}$ HCL solution.

\subsection{Sequential phosphorus fractionation}

Extractions obtained from sequential $\mathrm{P}$ fractionation reflect availability of each $\mathrm{P}$ fraction based on susceptibility to each extracting solution (Hedley et al., 1982; Table 2). Sequential fractionation was performed on soils sampled in 2003 (pretreatment) and 2013 (10 years post-treatment). Each sample was subjected to four separate extractions and a final digestion, providing five total fractions. Starting with $1.0 \mathrm{~g}$ of soil, a $0.5 \mathrm{M}$ buffered $\mathrm{NaHCO}_{3}$ solution was used to extract weaklyadsorbed inorganic P and organic P that is easily mineralized. A $0.1 \mathrm{M}$ $\mathrm{NaOH}$ solution was then utilized to extract inorganic and organic $\mathrm{P}$ that is more tightly sorbed to mineral surfaces, sesquioxides, and $\mathrm{P}$ associated with amorphous $\mathrm{Al}$ - and Fe-phosphates. A sonic bath was used in a second $0.1 \mathrm{M} \mathrm{NaOH}$ extraction to aid removal of inorganic and organic $\mathrm{P}$ held in internal surfaces of aggregates and mineral surfaces. Both fractions extracted using $\mathrm{NaOH}$ are considered slow-turnover $\mathrm{P}$ (Trasar-Cepeda et al., 1990). The final extraction used a $1.0 \mathrm{M} \mathrm{HCl}$ solution to remove any acid-soluble inorganic $\mathrm{P}$ in calcium-bound $\mathrm{P}$, which is considered to be mostly occluded and slow to become available. For total $\mathrm{P}$, a separate $0.25 \mathrm{~g}$ subsample was milled to a fine powder and digested using a Cu-catalyzed Kjeldahl digestion with $5 \mathrm{~mL}$ concentrated sulfuric acid, $0.15 \mathrm{~g} \mathrm{CuSO}_{3}$ and $1.5 \mathrm{~g} \mathrm{~K}_{2} \mathrm{SO}_{4}$ refluxed at $425^{\circ} \mathrm{C}$ for approximately $4 \mathrm{~h}$ (Taylor, 2000). Extracts and digestates from each $\mathrm{P}$ fraction were analyzed for P concentration on an ICP-AES (SPECTRO Analytical Instruments Gmbh, SPECTRO ARCOS ICP-AES, Kleve, Germany). Residual-P was calculated as the difference between total-P and the sum of the other four fractions. 
Table 3

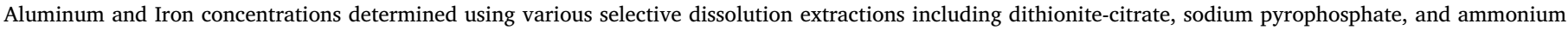
oxalate of soils sampled in 2003 at the $0-15 \mathrm{~cm}, 15-30 \mathrm{~cm}$, and $30-60 \mathrm{~cm}$ depths at Matlock and Molalla.

\begin{tabular}{|c|c|c|c|c|c|c|c|c|}
\hline & & \multicolumn{2}{|c|}{ Sodium pyrophosphate } & \multicolumn{3}{|c|}{ Ammonium oxalate } & \multicolumn{2}{|c|}{ Dithionite-citrate } \\
\hline & & $\mathrm{Al}(\%)$ & $\mathrm{Fe}(\%)$ & $\mathrm{Al}(\%)$ & $\mathrm{Fe}(\%)$ & $\mathrm{Al}+1 / 2 \mathrm{Fe}(\%)$ & $\mathrm{Al}(\%)$ & $\mathrm{Fe}(\%)$ \\
\hline \multirow[t]{3}{*}{ Matlock } & $0-15$ & $0.85(0.02)^{a}, b$ & $0.54(0.06)$ & $0.97(0.14)$ & $1.06(0.03)$ & 1.50 & $1.02(0.04)$ & $2.8(0.11)$ \\
\hline & $15-30$ & $0.83(0.02)$ & $0.40(0.02)$ & $1.11(0.01)$ & $0.95(0.04)$ & 1.59 & $1.01(0.02)$ & $2.5(0.10)$ \\
\hline & $30-60$ & $0.6(0.06)$ & $0.22(0.03)$ & $1.09(0.11)$ & $0.78(0.08)$ & 1.48 & $0.78(0.01)$ & $2.06(0.06)$ \\
\hline \multirow[t]{3}{*}{ Molalla } & $0-15$ & $1.45(0.13)$ & $0.48(0.06)$ & $1.76(0.19)$ & $0.69(0.03)$ & 2.11 & $1.15(0.08)$ & $2.78(0.17)$ \\
\hline & $15-30$ & $1.39(0.21)$ & $0.46(0.08)$ & $1.51(0.11)$ & $0.62(0.02)$ & 1.82 & $1.03(0.09)$ & $3.00(0.32)$ \\
\hline & $30-60$ & $1.07(0.17)$ & $0.36(0.09)$ & $1.24(0.23)$ & $0.57(0.06)$ & 1.53 & $0.83(0.05)$ & $3.19(0.24)$ \\
\hline
\end{tabular}

\footnotetext{
a Standard error of mean, $\mathrm{n}=3$.

b Probabilities in bold are significant $(\alpha=0.1)$.
}

\subsection{Selective dissolution extraction}

To further characterize soils at Matlock and Molalla selective dissolution extractions were used to determine soil $\mathrm{Al}$ and $\mathrm{Fe}$ concentrations associated with organometallic complexes and short-range order soil minerals (Wada, 1989). Soils sampled from the $0-15 \mathrm{~cm}, 15-30 \mathrm{~cm}$, and 30-60 cm depths in 2003 (pre-harvest) from both study sites were subjected to three different selective dissolution extractions according to the Kellogg soil survey laboratory methods manual (Soil Survey Staff, 2014a). Ditionite-citrate extractions were used to determine $\mathrm{Fe}$ and $\mathrm{Al}$ complexed with organic matter or associated with poorly-crystallized hydrous oxides and amorphous aluminosilicates (Wada, 1989). Ammonium oxide, although similar to Dithionite-Citrate, additionally extracts allophone. Finally, sodium pyrophosphate was used to primarily extract organically complexed $\mathrm{Fe}$ and $\mathrm{Al}$.

\subsubsection{Dithionite-citrate}

A $0.75 \mathrm{~g}$ sample of air-dry soil was extracted with $0.4 \mathrm{~g}$ sodium citrate and $25 \mathrm{~mL}$ of $0.57 \mathrm{M}$ sodium citrate solution in a $50 \mathrm{~mL}$ centrifuge tube. Samples were shaken overnight (12-16h), then centrifuged at $4000 \mathrm{rpm}$ for $15 \mathrm{~min}$. Extracts were diluted to a 1:20 ratio for $\mathrm{Fe}$ and $\mathrm{Al}$ using deionized water. Concentrations of $\mathrm{Al}$ and Fe were determined on an ICP-OES (Varian Vista MPX; Varian, Inc.; Palo Alto, CA).

\subsubsection{Ammonium oxalate}

A $0.5 \mathrm{~g}$ sample of air-dry soil was equilibrated for $30 \mathrm{~min}$ with $15 \mathrm{~mL}$ of $0.2 \mathrm{M}$ ammonium oxalate buffered to a $\mathrm{pH}$ of 3.0 in an extraction tube before a $30 \mathrm{~min}$ vacuum extraction of $10 \mathrm{~mL}$. Finally, an additional $35 \mathrm{~mL}$ of the ammonium oxalate solution was added to a reservoir tube secured to the top of the extraction tube and a total of $45 \mathrm{~mL}$ were vacuum extracted over the course of $12 \mathrm{~h}$ in the absence of light. Extracts were diluted to a 1:10 ratio using deionized water. Concentrations of $\mathrm{Al}$ and $\mathrm{Fe}$ were determined on an ICP-OES (Varian Vista MPX; Varian, Inc.; Palo Alto, CA).

\subsubsection{Sodium pyrophosphate}

A $0.5 \mathrm{~g}$ sample of air-dry soil was extracted with $30 \mathrm{~mL}$ of sodium pyrophosphate solution buffered to a $\mathrm{pH}$ of 10 in a $50 \mathrm{~mL}$ centrifuge tube. Samples were shaken overnight (12-16h), centrifuged at $4000 \mathrm{rpm}$ for $15 \mathrm{~min}$. Extracts were diluted to a 1:5 ratio with deionized water. Concentrations of $\mathrm{Al}$ and Fe were determined on an ICP-OES (Varian Vista MPX; Varian, Inc.; Palo Alto, CA).

\subsection{Statistical analysis}

Effect of treatments on soil $\mathrm{P}$ fraction concentrations for each depth were analyzed using a two-way factorial analysis of covariance (ANCOVA), with pre-harvest values used as a covariate, blocked for random effects, and using restricted maximum likelihood (REML) estimations. Changes from pre-harvest estimates of each P fraction were used as the primary response variable in most analyses, where change was calculated as the absolute arithmetic difference between pretreatment and 10-yr post-treatment estimates. We used the $90 \%$ confidence interval from each change estimate to independently determine if changes in $\mathrm{P}$ fractions were significantly different from zero for each treatment. When significant treatment interactions were found, multiple comparisons with Tukey's adjustment were conducted to detect differences between treatment means. Correlation analyses were used to explore associations between $\mathrm{P}$ fraction concentrations in the combined $0-30 \mathrm{~cm}$ depth and foliar nutrient concentrations under the different treatments. Finally, we used a simple $t$-test to determine significant differences in $\mathrm{Al}$ and $\mathrm{Fe}$, as extracted using $\mathrm{SDE}$, between the two sites. We used $\alpha=0.1$ for statistical significance because of low statistical power associated with the level of replication and high inherent variability in soil parameters, and conducted all analyses in JMP, Version 10 (SAS Institute Inc., Cary, NC 2014).

\section{Results}

\subsection{Selective dissolution extractions and pre-treatment phosphorus fractions}

$\mathrm{Al}$ and $\mathrm{Fe}$ concentrations extracted using selective dissolution methods were elevated at both sites (Table 3 ) and soils sampled from the $0-15 \mathrm{~cm}$ depth at Molalla meet the ammonium-oxalate extracted $\mathrm{Al}$ (\%) $+1 / 2 \mathrm{Fe}(\%)$ threshold (2\%) for Andic soil indicators (Soil Survey Staff, 2014b). Significant differences in $\mathrm{Al}$ and $\mathrm{Fe}$ concentrations at several depth and SDE method combinations were detected. Sodium pyrophosphate extracted a greater concentration of $\mathrm{Al}$ at Molalla than Matlock in the $0-15 \mathrm{~cm}$ and $30-60 \mathrm{~cm}$ depths. Ammonium oxalate extracted a greater concentration of $\mathrm{Al}$ but a lesser amount of $\mathrm{Fe}$ from Molalla soils compared to Matlock soils in the $0-15 \mathrm{~cm}$ and $15-30 \mathrm{~cm}$ depths. A greater concentration of Fe was extracted with DithioniteCitrate at Matlock than at Molalla in the $30-60 \mathrm{~cm}$ depth.

Soil P concentrations prior to treatment were generally higher at Matlock than at Molalla, and decreased with depth at both sites with the exception of the residual $\mathrm{P}$ fraction, which was relatively constant across depths (Fig. 1). After accounting for differences in fine fraction $(<2 \mathrm{~mm})$ bulk density, total $\mathrm{P}$ mass was comparable between sites (3.3 $\mathrm{Mg} \mathrm{ha}^{-1}$ at Matlock and $3.0 \mathrm{Mg} \mathrm{ha}^{-1}$ at Molalla; Table 1), which was surprising given the distinct differences in soil properties and productivity between sites (Table 1). Of all the fractions, only the moderately-recalcitrant and residual $\mathrm{P}$ fractions were similar between sites (Fig. 1). At both sites, Ca-bound $\mathrm{P}$ comprised the smallest proportion of total P concentration, accounting for $4.7 \%$ to $5.2 \%$ of total $\mathrm{P}$ at Matlock and $1.0 \%$ to $1.4 \%$ at Molalla. The largest P fraction at both sites and time periods was the $\mathrm{NaOH}$ extracted moderately-labile $\mathrm{P}$ fraction accounting for $60.8 \%$ to $63 \%$ and $52.4 \%$ to $58.9 \%$ of total P at Matlock and Molalla, respectively. 


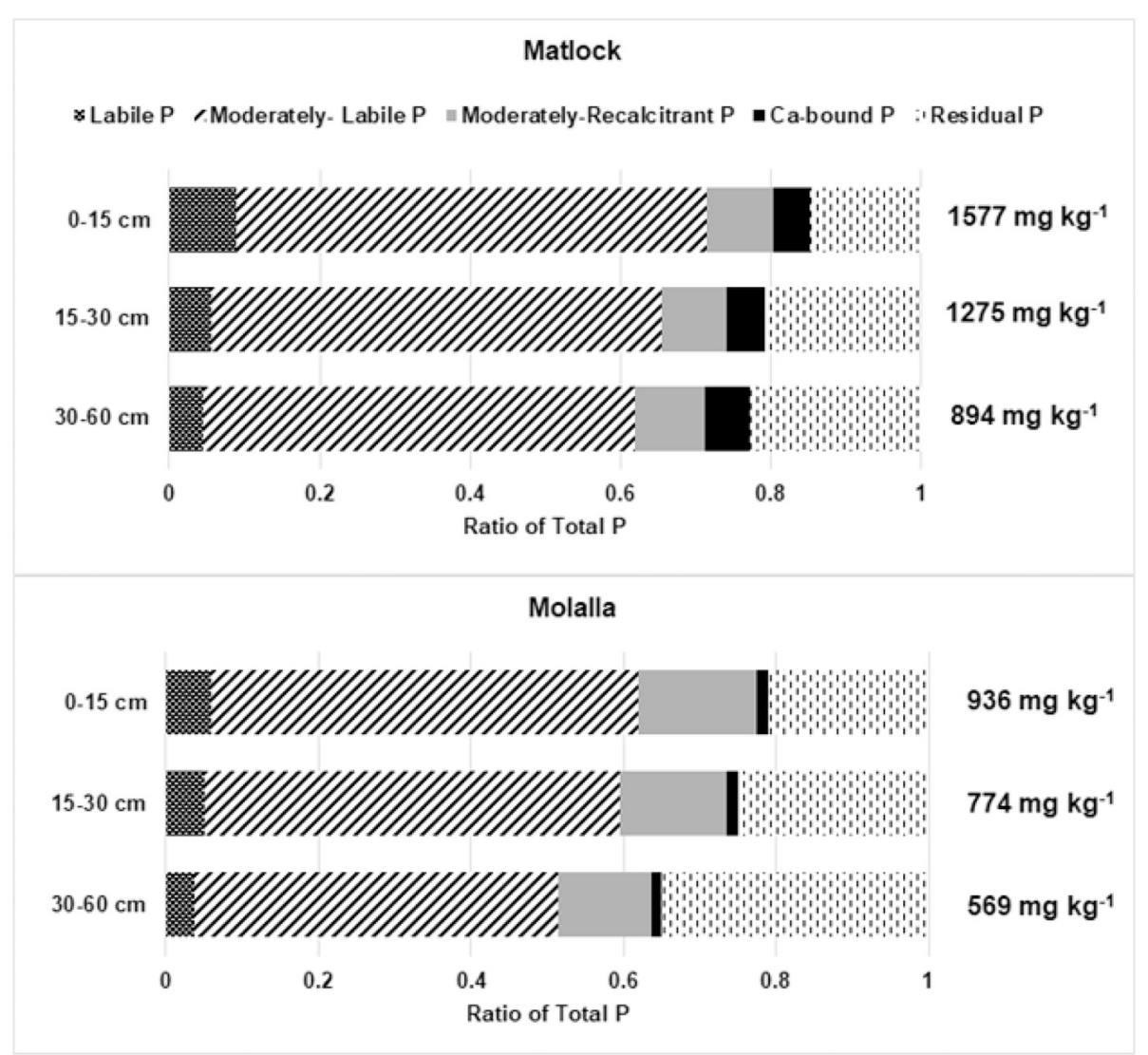

Fig. 1. Stacked bar graph of pre-harvest soil P fraction concentrations $\left(\mathrm{mg} \mathrm{kg}^{-1}\right)$, as a proportion of the soil total P concentration (shown on the right-hand side of each depth), by soil depth for Matlock and Molalla.

\subsection{Phosphorus fractionation - ten-year responses to treatment}

\subsubsection{Total $P$}

Ten-year responses at Matlock and Molalla showed primarily main effects of vegetation control on the change in total-P at most depths (Table 4). At Matlock, total soil $P$ in the $0-15 \mathrm{~cm}$ soil depth was significantly reduced in the AVC treatment over the ten-year period compared to the IVC treatment where total P did not change (Fig. 2). A similar effect of vegetation control was observed at $15-30 \mathrm{~cm}$ depth, but it was only significant in the $\mathrm{BO}$ harvest treatment (i.e., significant interaction, Table 4). At the 30-60 cm depth increment, main effects of both treatments were significant, which arose from a combination of positive change in total $\mathrm{P}$ in the IVC and BO treatments and negative change in the AVC and WT treatments (Fig. 2).

At Molalla, treatment effects on the change in total-P only occurred with vegetation control and were limited to the $0-15 \mathrm{~cm}$ and $15-30 \mathrm{~cm}$ depth increments. At both of those depths, there was a significant reduction in total P in the IVC treatment but not the AVC treatment (Fig. 2). Although there was no difference between harvest treatments, both harvest treatments had significant reductions in total $\mathrm{P}$ at the 0-15 cm and 15-30 cm depth increments over the ten-year assessment period (Fig. 2).

\subsubsection{Labile $P$}

At both sites, changes in labile $P$ were only associated with main effects of vegetation control at depths $>15 \mathrm{~cm}$ (Table 4, Fig. 2). Treatment effects were opposite at the sites, where the change in labile $\mathrm{P}$ was higher and positive with IVC at Matlock, but lower and negative with IVC at Molalla. A significant interaction between treatments at $0-15 \mathrm{~cm}$ followed this general pattern, except that differences between vegetation control treatments were only significant with the BO harvest intensity (Table 4). Estimated differences in labile $\mathrm{P}$ between vegetation control treatments ranged from approximately $24 \mathrm{mg} \mathrm{kg}^{-1}(15-30 \mathrm{~cm}$ depth) to $7 \mathrm{mg} \mathrm{kg}^{-1}$ (30-60 $\mathrm{cm}$ depth) at Matlock, and from $3 \mathrm{mg} \mathrm{kg}^{-1}$ (15-30 cm depth) to $2 \mathrm{mg} \mathrm{kg}^{-1}(30-60 \mathrm{~cm}$ depth) at Molalla.

\subsubsection{Moderately-labile $P$}

There were significant main effects of vegetation control on moderately-labile $P$ at both sites at the $0-15$ and $15-30 \mathrm{~cm}$ depths, and at $30-60 \mathrm{~cm}$ at Matlock only (Table 4). As with labile P, the responses were opposite between sites, with significantly positive and greater change with IVC at Matlock, and significantly positive and greater change with AVC at Molalla (Fig. 3). At Matlock, there was also a significant main effect of harvest treatment at $30-60 \mathrm{~cm}$, where responses differed by approximately $70 \mathrm{mg} \mathrm{kg}^{-1}$ between BO and WT harvests. No other harvest treatment differences were found at either site, but there were significant increases in moderately-labile $P$ at $15-30 \mathrm{~cm}$ in both harvest treatments at Matlock, and significant decreases at $0-15 \mathrm{~cm}$ for both harvest intensities at Molalla.

\subsubsection{Moderately-recalcitrant $P$}

For moderately-recalcitrant $P$, there was a significant treatment interaction at Matlock at the $15-30$ and $30-60 \mathrm{~cm}$ depths, but multiple comparisons did not reveal any significant differences among treatment combination means and there was no consistent trend in the response (see footnotes, Table 4). There was also no significant change in the moderately-recalcitrant $\mathrm{P}$ fraction for any treatment or depth at the Matlock site. In contrast, the change in moderately-recalcitrant $\mathrm{P}$ was significantly different between vegetation control treatments at all depths at the Molalla site (Fig. 3). In all cases, the IVC treatment was associated with significant reductions in moderately recalcitrant $P$ with little change in the AVC treatment over the ten-year period. There were no significant effects of harvest intensity on the change in moderatelyrecalcitrant $\mathrm{P}$ at Molalla, but the fraction was significantly reduced in 
Table 4

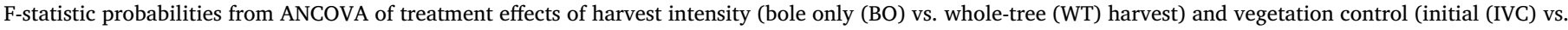

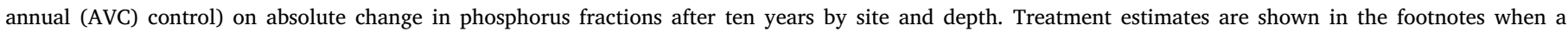
significant interaction was observed. All other estimates are shown in Figs. 2-4.

\begin{tabular}{|c|c|c|c|c|c|c|}
\hline Depth \& treatment effect & Total P & Labile P & Moderately-labile P & Moderately-recalcitrant P & Ca-bound P & Residual P \\
\hline \multicolumn{7}{|l|}{ Matlock } \\
\hline \multicolumn{7}{|l|}{$0-15 \mathrm{~cm}$} \\
\hline Veg. control & $0.094^{\mathrm{a}}$ & 0.073 & 0.087 & 0.280 & 0.052 & 0.651 \\
\hline Harvest intensity & 0.460 & 0.150 & 0.545 & 0.941 & 0.591 & 0.900 \\
\hline $\mathrm{VC}^{*} \mathrm{HI}^{\mathrm{b}}$ & 0.560 & $0.090^{\mathrm{d}}$ & 0.447 & 0.868 & 0.521 & 0.349 \\
\hline \multicolumn{7}{|l|}{$15-30 \mathrm{~cm}$} \\
\hline Veg. control & 0.041 & 0.026 & 0.039 & 0.874 & 0.068 & 0.280 \\
\hline Harvest intensity & 0.590 & 0.334 & 0.870 & 0.821 & 0.944 & 0.717 \\
\hline $\mathrm{VC} * \mathrm{HI}$ & $0.086^{c}$ & 0.338 & 0.124 & $0.043^{\mathrm{e}}$ & 0.862 & $0.058^{g}$ \\
\hline \multicolumn{7}{|l|}{$30-60 \mathrm{~cm}$} \\
\hline Veg. control & 0.001 & 0.058 & 0.001 & 0.652 & 0.301 & 0.131 \\
\hline Harvest intensity & 0.029 & 0.039 & 0.067 & 0.173 & 0.762 & 0.171 \\
\hline $\mathrm{VC} * \mathrm{HI}$ & 0.420 & 0.213 & 0.974 & $0.02^{f}$ & 0.433 & 0.487 \\
\hline \multicolumn{7}{|l|}{ Molalla } \\
\hline \multicolumn{7}{|l|}{$0-15 \mathrm{~cm}$} \\
\hline Veg. control & 0.050 & 0.061 & 0.077 & 0.077 & 0.131 & 0.838 \\
\hline Harvest intensity & 0.220 & 0.421 & 0.540 & 0.215 & 0.840 & 0.592 \\
\hline $\mathrm{VC} * \mathrm{HI}$ & 0.476 & $0.048^{\mathrm{h}}$ & 0.138 & 0.923 & 0.756 & 0.938 \\
\hline \multicolumn{7}{|l|}{$15-30 \mathrm{~cm}$} \\
\hline Veg. control & 0.023 & 0.480 & 0.004 & 0.0141 & 0.0761 & 0.062 \\
\hline Harvest intensity & 0.548 & 0.952 & 0.278 & 0.356 & 0.706 & 0.412 \\
\hline $\mathrm{VC}{ }^{*} \mathrm{HI}$ & 0.770 & 0.720 & 0.382 & 0.764 & 0.859 & 0.951 \\
\hline \multicolumn{7}{|l|}{$30-60 \mathrm{~cm}$} \\
\hline Veg. control & 0.131 & 0.363 & 0.264 & 0.095 & 0.483 & 0.651 \\
\hline Harvest intensity & 0.727 & 0.496 & 0.955 & 0.937 & 0.707 & 0.263 \\
\hline $\mathrm{VC} * \mathrm{HI}$ & 0.195 & 0.134 & 0.232 & 0.551 & 0.401 & 0.593 \\
\hline
\end{tabular}

a Probabilities in bold are significant $(\alpha=0.1)$.

b Significant vegetation control $x$ harvest intensity interaction.

c IVCXBO $=112 \mathrm{mg} \mathrm{kg}^{-1}$ AVCxBO $=-99 \mathrm{mg} \mathrm{kg}^{-1}$.

d IVCXBO $=31.7 \mathrm{mg} \mathrm{kg}^{-1}$ AVCxBO $=-15.9 \mathrm{mg} \mathrm{kg}^{-1}$.

e $\mathrm{IVCxBO}=5.6 \mathrm{mg} \mathrm{kg}^{-1}$ AVCxWT $=3.1 \mathrm{mg} \mathrm{kg}^{-1}$ AVCxBO $=-2.7 \mathrm{mg} \mathrm{kg}^{-1}$ IVCxWT $=-0.7 \mathrm{mg} \mathrm{kg}^{-1}$.

f $\mathrm{IVCxBO}=-15.5 \mathrm{mg} \mathrm{kg}^{-1} \mathrm{AVCxWT}=-10.7 \mathrm{mg} \mathrm{kg}^{-1} \mathrm{AVCxBO}=20.4 \mathrm{mg} \mathrm{kg}^{-1}$

IVCxWT $=-2.4 \mathrm{mg} \mathrm{kg}^{-1}$.

g IVCXBO $=-65.2 \mathrm{mg} \mathrm{kg}^{-1}$ AVCxBO $=-0.7 \mathrm{mg} \mathrm{kg}^{-1}$.

h $\mathrm{IVCxBO}=-2.1 \mathrm{mg} \mathrm{kg}^{-1} \mathrm{AVCxBO}=4.3 \mathrm{mg} \mathrm{kg}^{-1}$.

the BO treatment (Fig. 3).

\subsubsection{Ca-bound P}

At Matlock, there was a significant main effect of vegetation control on Ca-bound $P$ at the $0-15 \mathrm{~cm}$ and 15-30 depth increments (Table 4). In both instances, change in Ca-bound $\mathrm{P}$ was negative and significantly different from zero in the AVC treatment whereas change with IVC was positive (Fig. 4). At Molalla, the change in Ca-bound $\mathrm{P}$ was different between vegetation control treatments at $0-15 \mathrm{~cm}$ depths only, where IVC caused a significant reduction in the $\mathrm{P}$ fraction. With the exception of the AVC treatment at $0-15 \mathrm{~cm}$, all treatments and depths had significant reductions in the Ca-bound $\mathrm{P}$ fraction at Molalla, which were approximately $20-30 \%$ of pretreatment estimates (Fig. 4).

\subsubsection{Residual $P$}

There were no treatment effects on residual $P$ at Matlock, but all treatments were associated with significant reductions at the $15-30 \mathrm{~cm}$ depth increment (Table 4, Fig. 4). At Molalla, there were significant main effects of vegetation control at the $15-30 \mathrm{~cm}$ depth only. In this instance, the response (IVC > AVC) was opposite of that observed for other fractions, with the AVC treatment having a significant reduction in residual P (Fig. 4). With the exception of the IVC treatment at $15-30 \mathrm{~cm}$ depth, residual $\mathrm{P}$ was significantly reduced in all treatments at the $15-30 \mathrm{~cm}$ and $30-60 \mathrm{~cm}$ depths at Molalla.

\subsection{Foliar nutrition and correlations with $P$ fractions}

There were no significant treatment effects on $\mathrm{N}$ and $\mathrm{P}$ concentrations and N:P ratios in Douglas-fir foliage at either site, and no apparent trends in the response (data not shown). Foliar N concentrations across treatments were $1.28 \%( \pm 0.03)$ and $1.44 \%$ $( \pm 0.06)$ at Matlock and Molalla, respectively. Foliar P concentrations across treatments were $0.24 \%( \pm 0.01)$ and $0.21 \%( \pm 0.01)$ at Matlock and Molalla, respectively. Mean foliar N:P ratios were 5.3 $( \pm 0.3)$ at Matlock, and $7.0( \pm 0.6)$ at Molalla.

We limited the foliar-P fraction correlation assessment to the vegetation control treatments only (pooled across both harvest treatments). For this assessment, we used a mean $\mathrm{P}$ fraction value for $0-30 \mathrm{~cm}$ from samples collected at the ten-year post-treatment period. At Matlock, there were no significant correlations between any of the foliar variables ( $\mathrm{N} \%, \mathrm{P} \%$, and $\mathrm{N}: \mathrm{P})$ and $\mathrm{P}$ fractions in the IVC treatment (data not shown), but there was a significant positive correlation in the AVC treatment between the ten-year moderately-recalcitrant $\mathrm{P}$ fraction and foliar $\mathrm{P}$ concentration $(r=0.82, p=.013)$. At Molalla, the Cabound $\mathrm{P}$ fraction was negatively correlated with foliar $\mathrm{N}$ concentration $(r=-0.66, p=.074)$. There were no other significant correlations among any of the $\mathrm{P}$ fraction and foliar variables (data not shown).

\section{Discussion}

Our results indicate potential for reductions in soil $\mathrm{P}$ fractions over time with the more intensive practices of WT harvest and AVC at Matlock. In contrast, most of the treatments at Molalla reduced $\mathrm{P}$ fractions except for the AVC treatment, where P fractions were either maintained or increased in some instances. Although decreases were detected, total P concentrations of surface soils after ten years were still 


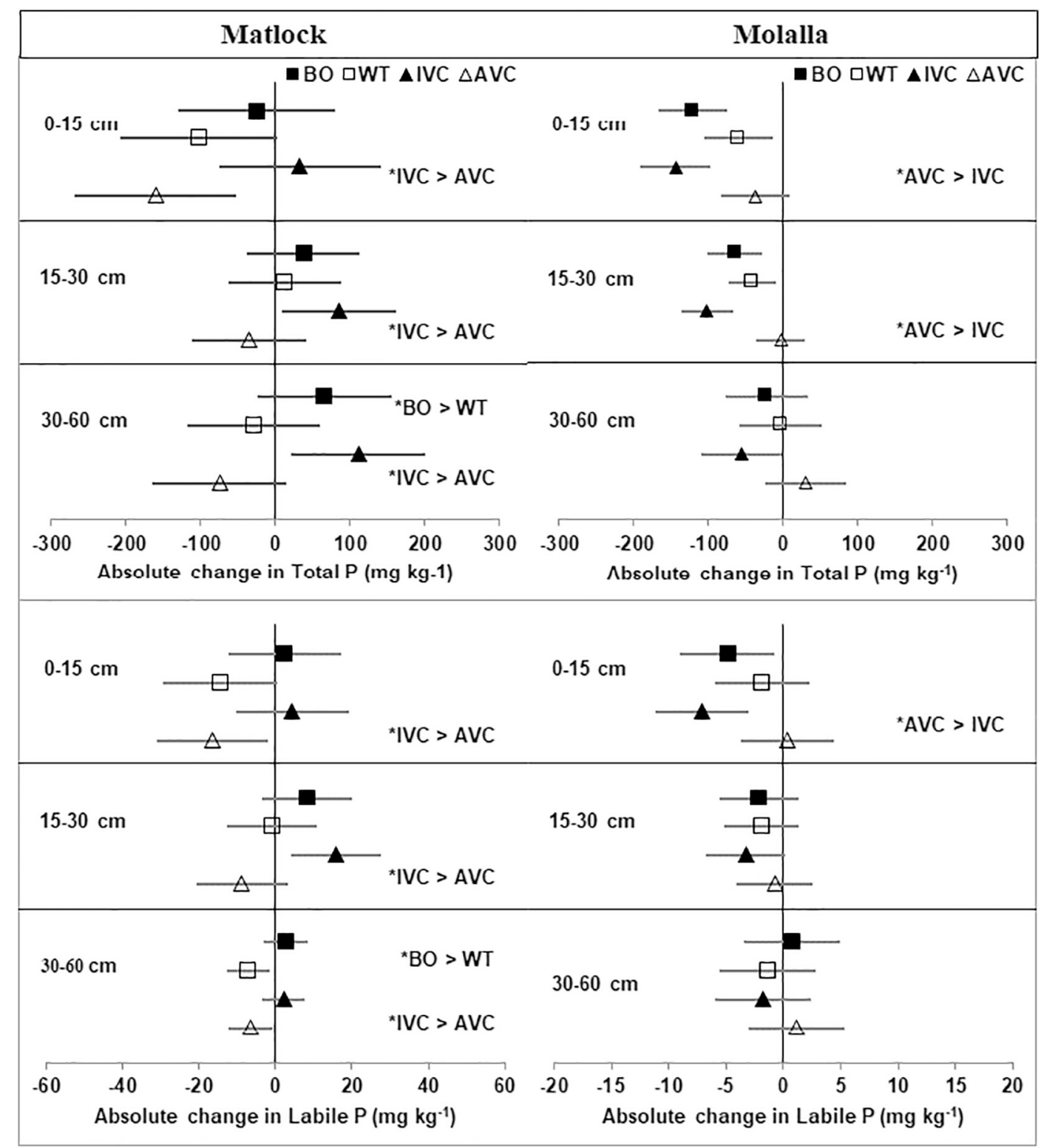

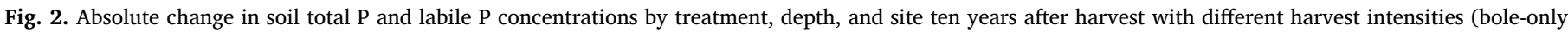

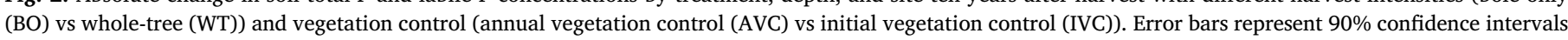
for each least squares mean with significant differences indicated by an asterisk. Note differences in scale between sites for the labile P fraction.

relatively high at both sites $\left(1500 \mathrm{mg} \mathrm{kg}^{-1}\right.$ and $970 \mathrm{mg} \mathrm{kg}^{-1}$ at $0-15 \mathrm{~cm}$ at Matlock and Molalla, respectively) in comparison to total $\mathrm{P}$ of $120 \mathrm{mg} \mathrm{kg}^{-1}$ for some prairie soils (Caldwell, 2006) and $134 \mathrm{mg} \mathrm{kg}^{-1}$ for loblolly pine (Pinus taeda) stands in the southeastern U.S. (Kiser, 2011). Given the relatively large P reserves at our sites, and the small amount of ecosystem P removed in both harvest treatments, it seems unlikely that harvest intensity will induce P limitations to productivity over the course of multiple rotations.

Comparisons of the individual fraction ratios with those of the Walker and Syers (1976) model indicate these sites have nearly exhausted reserves of Ca-bound P, which occurs at nearly 20,000 years in some chronosequences (Crews et al., 1995). Relatively lesser amounts of Ca-bound P at Molalla indicate more weathered soils compared to Matlock. Correspondingly, increased proportions of moderately-labile P and residual $P$ fractions at Molalla further support this.

The large proportion of moderately-labile $\mathrm{P}$ at both sites is in agreement with the findings of Yang and Post (2011), who concluded that this fraction was a significant proportion across most soil orders and weathering stages. Additionally, the significant labile and moderately-labile pools may be a result of the presence of high contents of $\mathrm{Fe}$ and $\mathrm{Al}$ associated with hydrous oxides, amorphous alumnosilicates, and organometallic complexes as determined by our selective dissolution extraction. These minerals and complexes are generally considered to be highly reactive with soil $\mathrm{P}$ and likely represent a plant available pool (Saunders, 1964; Hodges and Zelazny, 1980; Borggaard et al., 1990; Guo and Yost, 1998; Harsh et al., 2002). Our SDE analysis showed a significantly greater concentration of $\mathrm{Al}$ as extracted by both sodium pyrophosphate and ammonium oxalate at Molalla than at Matlock. If both extractions are associated with organo-metallic complexes and short-range order minerals (Wada, 1989), respectively, we would also expect the Molalla soils to be more retentive of soil $\mathrm{P}$ compared with Matlock (Saunders, 1964; Hodges and Zelazny, 1980), especially since reactive $\mathrm{Al}$ content would be even higher at Molalla (i.e., higher clay content and lower coarse fragment content at Molalla; Table 1). This, however, does not appear to be directly supported by this study as Molalla soils contained a lower concentration and lower total content of 


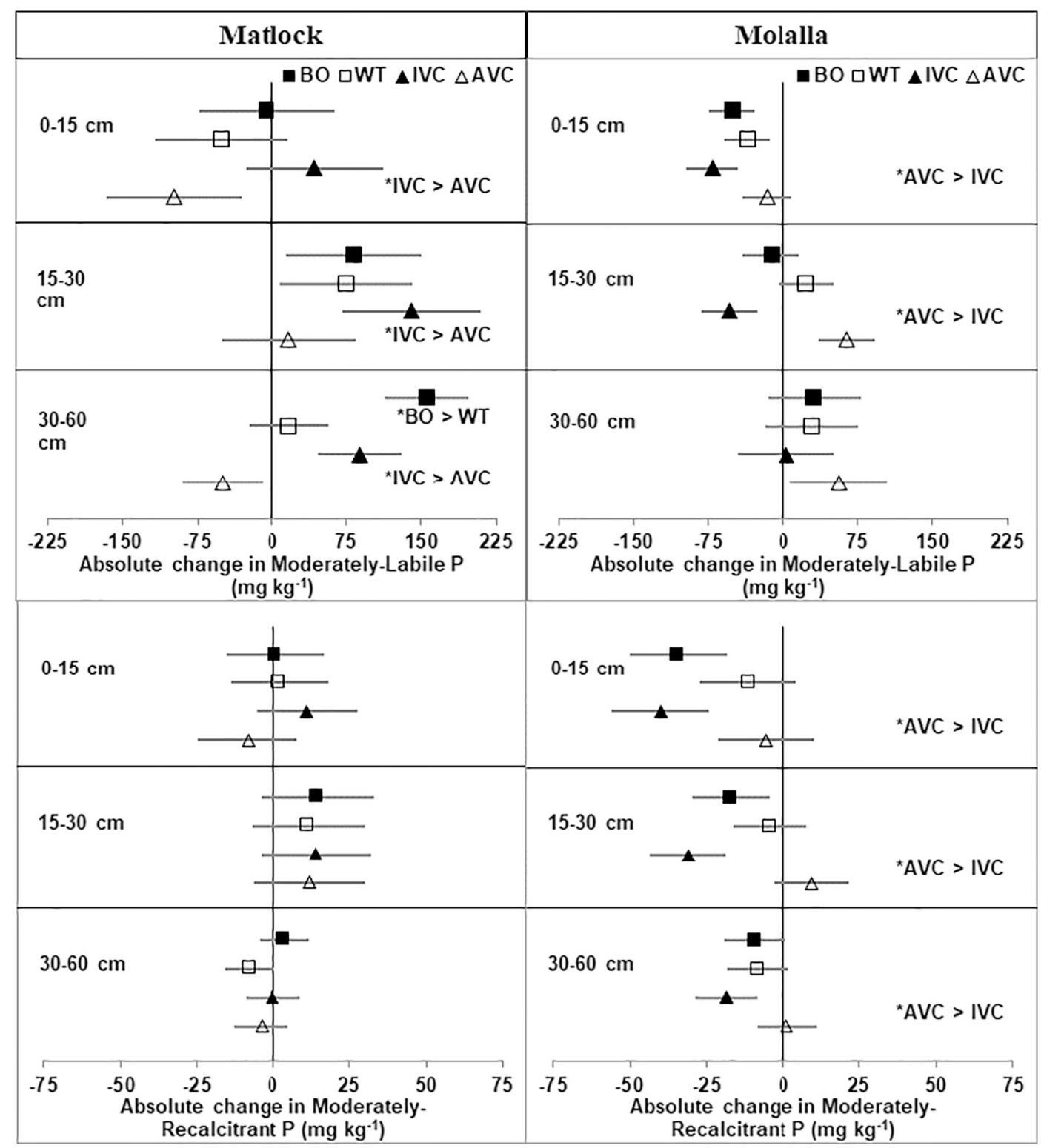

Fig. 3. Absolute change in soil moderately-labile $P$ and moderately-recalcitrant $P$ concentrations by treatment, depth, and site ten years after harvest with different harvest intensities (bole-only (BO) vs whole-tree (WT)) and vegetation control (annual vegetation control (AVC) vs initial vegetation control (IVC)). Error bars represent $90 \%$ confidence intervals for each least squares mean with significant differences indicated by an asterisk.

soil $\mathrm{P}$ fractions. Additionally, there were a greater number of significant decreases in P fractions at Molalla than at Matlock. Only ammonium oxalate extracted Fe concentration was greater at Matlock than Molalla. This suggests some other mechanism, besides the differences in the preharvest concentrations of $\mathrm{Al}$ and $\mathrm{Fe}$ associated with poorly crystalline minerals, is responsible for the contrasting responses of some of the $\mathrm{P}$ fractions to treatments. One possibility is $\mathrm{Fe}$ and $\mathrm{Al}$ concentrations in post-harvest samples may have responded to the different harvest and herbicide treatments (not measured in this study). Effects on Fe and $\mathrm{Al}$ contents have been observed in a long-term (44 years) study where increases in $\mathrm{P}$ associated with amorphous forms of $\mathrm{Al}$ and $\mathrm{Fe}$, were positively correlated with manure fertilization (Pizeeghello et al., 2014). Additionally, because of the differences in bulk densities at these sites, trends in soil $\mathrm{P}$ fraction content with soil $\mathrm{Fe}$ and $\mathrm{Al}$ content (not explored in this study) may differ from those explored in terms of concentration.

Phosphorus fractions generally decreased with depth at both Matlock and Molalla prior to harvest, which is consistent with observations across a variety of managed systems (Spears et al., 2001;
Wang et al., 2007; Maranguit et al., 2017). One exception to this trend is the typical increase in Ca-bound P with depth (Chen, 2003) that is associated with increases in soil $\mathrm{pH}$. Ca-bound $\mathrm{P}$ did not increase with depth at our sites even though soil pH did (Table 1), suggesting a different geochemical control in these subsoils compared to other managed systems, such as a greater content of poorly-crystalline minerals. Wood et al., 1984, showed that the $\mathrm{HCl}$ could solubilize Fe bound P associated with poorly crystalline minerals. Our SDE analysis showed typical decreases in ammonium oxalate extractible Fe concentrations with increasing depth which is matched with decreases in Ca-bound P with increasing depth.

In addition, the residual-P fraction concentration remained relatively consistent across depths at both sites but the ratio of residual $\mathrm{P}$ to total P increased. Compton and Cole (1998) observed a similar trend and suggested if the residual $\mathrm{P}$ pool is primarily organic $\mathrm{P}$, it may represent a significant source of labile $\mathrm{P}$ available to plants (Johnson et al., 2003; Gahoonia and Nielsen, 1992). Although we did not quantify the proportion of organic $\mathrm{P}$ in the residual pool, the general treatment responses indicate that most of the changes in $\mathrm{P}$ fractions are 


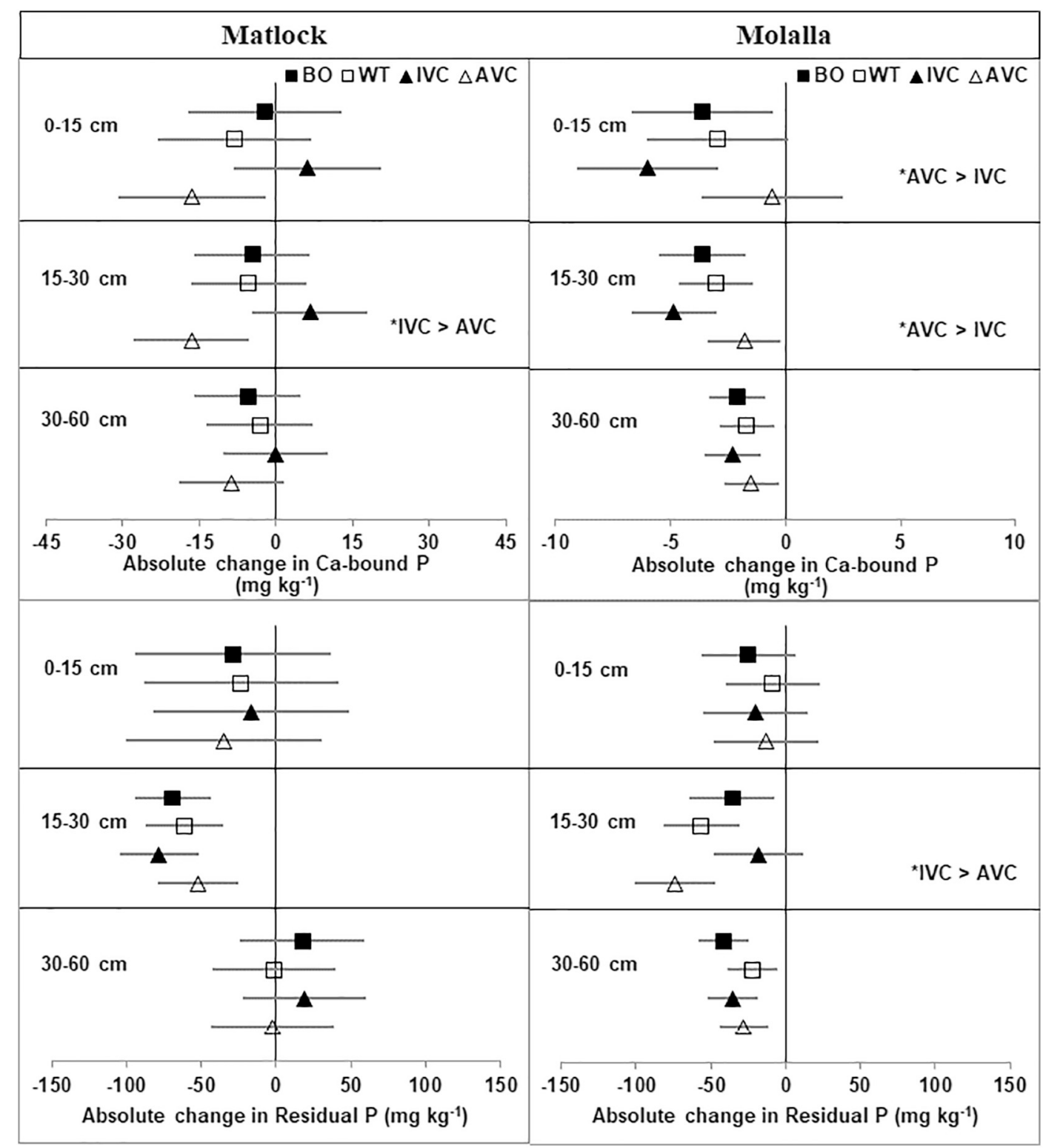

Fig. 4. Absolute change in soil Ca-bound $\mathrm{P}$ and residual $\mathrm{P}$ concentrations by treatment, depth, and site ten years after harvest with different harvest intensities (boleonly (BO) vs whole-tree (WT)) and vegetation control (annual vegetation control (AVC) vs initial vegetation control (IVC)). Error bars represent $90 \%$ confidence intervals for each least squares mean with significant differences indicated by an asterisk. Note differences in scale between sites for the Ca-bound P fraction.

associated with the relative amount of vegetation present, suggesting that biological controls are highly important to changes in the P fractions and cycling at these sites.

Because most treatment effects were associated with the vegetation control treatment, differences in site-specific responses to treatments are likely associated with differences in vegetative communities among treatments and between sites, and their interactions with physio-chemical characteristics of each soil. For example, Scotch broom cover at Matlock was extensive and significantly greater in WT than in BO throughout the study period (D. Peter and T. Harrington, unpublished data). Scotch broom is an N-fixing invasive plant capable of increasing phosphatase activity and decreasing total $\mathrm{P}$ (Caldwell, 2006). At Matlock in the $30-60 \mathrm{~cm}$ depth, total $\mathrm{P}$, labile $\mathrm{P}$, and moderately labile $\mathrm{P}$ each were lower in WT than in $\mathrm{BO}$, which could have resulted from greater uptake of plant-available $\mathrm{P}$ by the rapidly growing Scotch broom. Although isolated patches of Scotch broom were found at Molalla, Scotch broom cover did not vary significantly by harvest intensity or vegetation control treatments. In a small-plot $\left(28 \mathrm{~m}^{2}\right)$ study focused on presence versus absence of Scotch broom, Slesak et al. (2016a) found that the moderately-available $\mathrm{P}$ fraction was reduced in the presence of Scotch broom at Matlock, but not at Molalla. Slesak et al. (2016a) reported that plots at Matlock were located in a uniform stand of Scotch broom, whereas plots at Molalla were centered on individual Scotch broom plants. Giardina et al. (1995), found that phosphatase activity and available $\mathrm{P}$ were higher under a mixed-species Douglas-fir stand in the presence of $\mathrm{N}$-fixing red alder, which is more similar to the uniform Douglas-fir/Scotch broom mixture at Matlock. Given the above, reductions in P with WT at Matlock are likely driven indirectly by the influence of that treatment on Scotch broom abundance rather than a direct result of increased $P$ removal at time of harvest.

At Molalla, nutrient uptake by vegetation in general may have played a larger role in soil $\mathrm{P}$ changes over the ten-year study period. Phosphorus fractions are generally smaller (Fig. 1), and site productivity higher, at Molalla compared to Matlock (Slesak et al., 2016b). This relatively greater imbalance between P supply and demand could lead to the observed $\mathrm{P}$ reductions in soil. Increased or maintained $\mathrm{P}$ fractions in the AVC treatment supports this, because total vegetation (Douglas-fir and competition) uptake in that treatment would have 
been much lower compared to the IVC treatment. Treatment-induced shifts in community composition could have also contributed to the response at Molalla (Peter and Harrington, 2012).

Maintained or increased labile and moderately labile P at Matlock at the $30-60 \mathrm{~cm}$ depths in the BO harvest treatment might be attributed to the direct effect of debris on the amount of $\mathrm{P}$ removed during harvest, its indirect influence on belowground decomposition (Devine and Harrington, 2007; Sanchez et al., 2006), or the rate at which plants access $\mathrm{P}$ and translocate it to surface soils (Eger et al., 2018). The response may also be associated with the aforementioned Scotch broom effect because the BO treatment had a markedly lower amount of Scotch broom present at the Matlock site (Harrington and Schoenholtz, 2010; D. Peter and T. Harrington, unpublished data). Greater overall P retention with $\mathrm{BO}$ harvest or increased P cycling with broom (Caldwell, 2006; McGill and Cole, 1981) would allow for greater stand uptake, but some of the available P would be fixed onto mineral surfaces and lead to the observed increases.

Relative decreases in labile P, coupled with increases in exchangeable Ca measured at the same time as this study (Slesak et al., 2016b) could indicate precipitation of calcium phosphates in these soils (Tan, 1982). Giardina et al. (1995) also found increases in soil-solution $\mathrm{Ca}^{2+}$ and phosphates, which were correlated with greater concentrations of Ca-bound P. However, we did not measure any increases in the Cabound $\mathrm{P}$ fraction. Organic molecules in solution also occlude phosphate compounds and $\mathrm{Ca}^{2+}$ from dissolution during fractionation (Lindsay, 1979; Giardina et al., 1995). Similar studies to ours (Cross and Schlesinger, 1995; Giardina et al., 1995) suggest that the Ca-bound P fraction, extracted by $\mathrm{HCl}$, may include other $\mathrm{HCl}$-soluble compounds besides primary mineral $\mathrm{P}$ and calcium phosphates such as $\mathrm{HCl}$ soluble $\mathrm{Fe}$ and $\mathrm{Al}$ bound $\mathrm{P}$ as mentioned previously mentioned in this discussion. Further evidence of this possibility was provided by He et al. (2006), who used an enzymatic assay analysis paired with oxidative autoclaving to show that some soil samples contained significant organic $\mathrm{P}$ concentrations in the $\mathrm{HCl}$-extracted fraction. This exemplifies the difficulty in interpreting the degree of availability or occlusion within these fractions (Condron and Newman, 2011).

Decreases in residual $\mathrm{P}$ over the ten-year study period were observed across most treatment and depth combinations at both sites relative to the pre-treatment concentrations. These decreases were likely related to shifts in $\mathrm{P}$ demand associated with changes in vegetative nutrient demand between pre-harvest and year 10 (Vitousek et al., 2010). The residual $P$ fraction is generally considered unavailable (Cross and Schlesinger, 1995). However, recent studies have shown the residual fraction may be more available than previously reported (Condron and Newman, 2011; Vitousek et al., 2010), especially in slightly weathered soils (Guo et al., 2000). This fraction has been shown to support plant growth in forests and to turn-over significantly during a 65-year period (Hedley et al., 1982; Chen et al., 2000; Chatterjee et al., 2013).

Low correlations between soil P pools and foliar P in Douglas-fir in this study suggest plots with higher soil $\mathrm{P}$ do not necessarily supply more P to Douglas-fir trees growing on these sites, which is further supported by lack of treatment effects on foliar N and P. Low N:P in foliage $(<10)$ at both sites and all treatment plots indicates $\mathrm{N}$ limitation is more likely than a P limitation (Güsewell, 2004). In addition, foliar P concentrations at both sites were above levels considered adequate for growth (Ballard and Carter, 1986). Therefore, it is likely that $\mathrm{P}$ is not limiting to plant growth in these soils, but risks of $\mathrm{P}$ limitation may be higher at the Molalla site relative to the younger Matlock site (Root, 2017). Nonetheless, the Molalla site shows little evidence of developing $\mathrm{P}$ deficiencies in the near future compared to some forested ecosystems (Crews et al., 1995; Riley and Vitousek, 1995; Vitousek and Farrington, 1997).

\section{Conclusions}

Results of this study identified changes in soil $\mathrm{P}$ fraction concentrations at $0-60 \mathrm{~cm}$ during the first 10 years of Douglas-fir stand growth, depending on site characteristics, harvest intensity, and vegetation control treatments. We also detected significant differences in $\mathrm{Al}$ and Fe concentrations as extracted by sodium pyrophosphate and ammonium oxalate between the two sites. The less-intensive treatments of $\mathrm{BO}$ harvesting and vegetation control limited to the first year after tree planting (IVC) at Matlock ameliorated many of the decreases in $\mathrm{P}$ fraction concentrations, whereas five years of annual vegetation control mediated decreases in $\mathrm{P}$ concentrations at Molalla. The contrasting responses to vegetation control at these sites suggest that vegetation abundance and composition has an overwhelming influence on soil $\mathrm{P}$ fraction dynamics following harvest. On-site observations at year-ten included less abundance of the invasive Scotch broom under BO harvest than WT harvest at Matlock. Therefore, on sites where BO is effective in reducing Scotch broom and other invasive species, this treatment may be preferred to VC; as both broom cover and soil P loss were reduced. In contrast, sites such as Molalla, where harvest intensity had little influence on the vegetation community, VC may be preferred. These responses and changes in fractions most associated with organic $\mathrm{P}$ suggest that biologic controls of $\mathrm{P}$ pools are more important than geochemical ones at these two sites, despite elevated concentrations of $\mathrm{Fe}$ and $\mathrm{Al}$ extracted with SDE methods. With high foliar P concentrations, low $\mathrm{N}: \mathrm{P}$, and the lack of consistent positive correlations between $\mathrm{P}$ fraction concentrations and foliar P concentrations, there is little evidence to suggest more intensive harvesting has an effect on foliar nutrition at these sites, and therefore little effect on productivity by way of $\mathrm{P}$ nutrition manipulation. Continued analysis of changes in $\mathrm{P}$ fractions and cycling in response to contrasting management regimes and across more site conditions is needed to understand if these $\mathrm{P}$ pools change over longer periods of time more relevant to ecosystem development and management (i.e., rotation length).

\section{Acknowledgements}

This is a product of the Sustainable Forestry component of Agenda 2020, a joint effort of the USDA Forest Service Research and Development and the American Forest and Paper Association. Funds were provided by the USDA Forest Service Pacific Northwest Research Station, Virginia Tech, Green Diamond Resource Company, and Port Blakely Tree Farms, LLC. The authors are grateful to Randall Greggs and Mike Warjone for providing critical financial and logistical support that made this study possible. Special thanks to J. Dollins for assisting with field work and sample preparation, and Stephanie Duston for her assistance in the laboratory.

\section{References}

Adams, W.T., Hobbs, S., Johnson, N., 2005. Intensively managed forest plantations in the Pacific northwest: introduction. J. For. 103, 59-60.

Ballard, T.M., Carter, R.E., 1986. Evaluating Forest Stand Nutrient Status. vol. 20. Land Management Rep, B.C. Min. Forests, Victoria, pp. 60.

Borggaard, O.K., Jdrgensen, S.S., Moberg, J.P., Raben-Lange, B., 1990. Influence of organic matter on phosphate adsorption by aluminium and iron oxides in sandy soils. J. Soil Sci. 41, 443-449.

Boyle, J.R., Ek, A.R., 1972. An evaluation of some effects of bole and branch pulpwood harvesting on site macronutrients. Can. J. For. Res. 2, 407-412.

Caldwell, B.A., 2006. Effects of invasive scotch broom on soil properties in a Pacific coastal prairie soil. Appl. Soil Ecol. 32, 149-152.

Celi, L., Cerli, C., Turner, B.L., Santoni, S., Bonifacio, E., 2013. Biogeochemical cycling of soil phosphorus during natural revegetation of Pinus sylvestris on disused sand quarries in northwestern Russia. Plant Soil 367, 121-134.

Chappell, H.N., Cole, D.W., Gessel, S.P., Walker, R.B., 1991. Forest fertilization research and practice in the Pacific northwest. Fert. Res. 27, 129-140.

Chatterjee, D., Datta, S.C., Manhaiah, K.M., 2013. Clay carbon pools and their relationship with short-range order minerals: avenues to mitigate climate change? Curr. Sci. 105 (10), 1404.

Chen, H., 2003. Phosphatase activity and P fractions in soils of an 18-year-old Chinese fir 
(Cunninghamia lanceolata) plantation. Forest Ecol. Manag. 178, 301-310.

Chen, H., Harmon, M.E., Griffiths, R.P., Hicks, W., 2000. Effects of temperature and moisture on carbon respired from decomposing woody roots. For. Ecol. Manag. 138, $51-64$.

Compton, J.E., Cole, D.W., 1998. Phosphorus cycling and soil P fractions in Douglas-fir and red alder stands. For. Ecol. Manag. 110, 101-112.

Condron, L.M., Newman, S., 2011. Revisiting the fundamentals of phosphorus fractionation of sediments and soils. J. Soils Sediments 11, 830-840.

Crews, T.E., Kitayama, K., Fownes, J.H., Riley, R.H., Herbert, D.A., Mueller-Dombois, D., Vitousek, M., 1995. Changes in soil phosphorus fractions and ecostsyem dynamics across a long chronosequence in Hawaii. Ecology 76, 1407-1424.

Cross, A.F., Schlesinger, W.H., 1995. A literature review and evaluation of the Hedley fractionation: applications to the biogeochemical cycle of soil phosphorus in natural ecosystems. Geoderma 64, 197-214.

Devine, W.D., Harrington, C.A., 2007. Influence of harvest residues and vegetation on microsite soil and air temperatures in a young conifer plantation. Agric. For. Meteorol. 145, 125-138.

Devine, W.D., Harrington, T.B., Terry, T.A., Harrison, R.B., Slesak, R.A., Peter, D.H., Harrington, C.A., Shilling, C.J., Schoenholtz, S.H., 2011. Five-year vegetation control effects on aboveground biomass and nitrogen content and allocation in Douglas-fir plantations on three contrasting sites. For. Ecol. Manag. 262, 2187-2198.

Eger, A., Yoo, K., Almond, P.C., Boitt, G., Larsen, I.J., Condron, L.M., Wang, X., Mudd, S.M., 2018. Does Erosion rejuvenate the soil phosphorus inventory? Geoderma 332, 45-59.

Gahoonia, T.S., Nielsen, N.E., 1992. The effects of root-induced pH changes on the depletion of inorganic and organic phosphorus in the rhizosphere. Plant Soil 143, 185-191.

Giardina, C.P., Huffman, S., Binkley, D., Caldwell, B.A., 1995. Alders increase soil phosphorus availability in a Douglas-fir plantation. Can. J. For. Res. 25, 1652-1657.

Guo, F., Yost, R.S., 1998. Partitioning soil phosphorus into three discrete pools of differing availability. Soil Sci. Soc. Am. J. 163, 822-833.

Guo, F., Yost, R.S., Huw, N.V., Evensen, C.I., Silva, J.A., 2000. Changes in phosphorus fractions in soils under intensive plant growth. Soil Sci. Soc. Am. J. 64, 1681-1689.

Güsewell, S., 2004. N: P ratios in terrestrial plants: variation and functional significance. New Phytol. 164, 243-266.

Harrington, T.B., Schoenholtz, S.H., 2010. Effects of logging debris treatments on fireyear development of competing vegetation and planted Douglas-fir. Can. J. For. Res. 40, 500-510.

Harsh, J., Chorover, J., Nizeyimana, E., 2002. Allophane and imogolite. In: Dixon, J.B., Schulze, D.G. (Eds.), Soil Mineralogy with Environmental Applications. Soil Sci. Soc. of Am. Book Series, vol. 7. pp. 291-322 Madison, WI.

He, Z., Fortuna, A., Senwo, Z.N., Tazisong, I.A., Honeycutt, C.W., Griffin, T.S., 2006. Hydrochloric Fractions in Hedley Fractionation May Contain Inorganic and Organic Phosphates.

Hedley, M.J., Stewart, J.W.B., Chauhan, B.S., 1982. Changes in inorganic and organic soil phosphorus fractions induced by cultivation practices and by laboratory incubations. Soil Sci. Soc. Am. J. 46, 970-976.

Hodges, S., Zelazny, L.W., 1980. Determination of noncrystalline soil components by weight difference after selective dissolution. Clay Clay Miner. 28, 35-42.

Holub, S.M., Terry, T.A., Harrington, C.A., Harrison, R.B., Meade, R., 2013. Tree growth ten years after residual biomass removal, soil compaction, tillage, and competing vegetation control in a highly-productive Douglas-fir plantation. For. Ecol. Manag. 305, 60-66.

Houlton, B.Z., Wang, Y.P., Vitousek, P.M., Field, C.B., 2008. A unifying framework for dinitrogen fixation in the terrestrial biosphere. Nature 454, 327-330.

Ilg, K., Wellbrock, N., Lux, W., 2009. Phosphorus supply and cycling at long-term forest monitoring sites in Germany. Eur. J. For. Res. 128, 483-492.

Johnson, A.H., Frizano, J., Vann, D.R., 2003. Biogeochemical implications of labile phosphorus in forest soils determined by the Hedley fractionation procedure. Oecologia 135 (4), 487-499.

Kiser, L.C., 2011. Nutrient Retention and Cycling in Southeastern U.S. Loblolly Pine (Pinus taeda L.) and Sweetgum (Liquidambar styraciflua L.) Plantations. Doctoral Dissertation. Virginia Polytechnic and State University. http://scholar.lib.vt.edu/ theses/available/etd-09152011-094724/.

Lindsay, W.L., 1979. Chemical equilibria in soils. John Wiley \& Sons, Inc, New York.

Maranguit, D., Guillaume, T., Kuzyakov, Y., 2017. Land-use change affects phosphorus fractions in highly weathered tropical soils. Catena 149 (385-292).

McGill, W.B., Cole, C.V., 1981. Comparative aspects of cycling of organic C, N, S, and P through soil organic matter. Geoderma 26, 267-286.

Peter, D.H., Harrington, T.B., 2012. Relations of Native and Exotic Species 5 Years after Clearcutting with and without Herbicide and Logging Debris Treatments. Res. Pap. PNW-RP-589. U.S. Department of Agriculture, Forest Service, Pacific Northwest Research Station, Olympia, WA.

Pizeeghello, D., Berti, A., Nardi, S., Morari, F., 2014. Phosphorus-related properties in the profiles of three Italian soils after long-term mineral and manure applications. Agric. Ecosyst. Environ. 189, 216-228.

Powers, R.F., Alban, D.H., Miller, R.E., Tiarks, A.E., Wells, C.G., Avers, P.E., Cline, R.G.,
Fitzgerald, R.O., Loftus Jr., N.S. 1990. Sustaining site productivity in north American forests: Problems and prospects. In: Gessel, S.P. et al. (Eds.), Sustained Productivity of Forest Soils. Forestry Publications, University of British Columbia, Vancouver, BC, pp. 49-80.

Powers, R.F., Scott, D.A., Sanchez, F.G., Voldseth, R.A., Page-Dumroese, D., Elioff, J.D., Stone, D.M., 2005. The North American long-term soil productivity experiment: findings from the first decade of research. For. Ecol. Manag. 220, 31-50.

Riley, R.H., Vitousek, P.M., 1995. Nutrient dynamics and nitrogen trace gas flux during ecosystem development in montane rain Forest. For. Ecol. Manag. 76, 292-304.

Robertson, G., Sollins, P., Ellis, B., Lajtha, K., 1999. Exchangeable ions, pH, and cation exchange capacity. In: Robertson, G. (Ed.), Standard Soil Methods for Long-Term Ecological Research. Oxford Univ. Press, New York, pp. 106-114.

Root, A.M., 2017. The Effects of Biomass Removal and Vegetation Control on Douglas-Fir Foliar Nitrogen and Phosphorus in the Pacific Northwest, USA. MSc. Thesis. University of Washington, Seattle WA.

Sanchez, F.G., Powers, R.F., Sanborn, P.T., Chapman, W.K., Tiarks, A.E., Kranabetter, J.M., Page-Dumroese, D.S., 2006. Effects of organic matter removal and soil compaction on fifth-year mineral soil carbon and nitrogen contents for sites across the United States and Canada. Can. J. For. Res. 36, 565-576.

Saunders, W.M.H., 1964. Phosphate retention by New Zealand soils and its relationship to free sesquioxides, organic matter and other soil properties. N. Z. J. Agric. Res. 8, 30-57.

Schlesinger, W.H., Bruijnzeel, L.A., Bush, M.B., Klein, E.M., Mace, K.A., Raikes, J.A., Whittaker, R.J., 1998. The biogeochemistry of phosphorus after the first century of soil development on Rakata Island, Krakatau, Indonesia. Biogeochemistry 40, 37-55.

Sharpley, A.N., Smith, S.J., 1985. Fractionation of inorganic and organic phosphorus in virgin and cultivated soils. Soil Sci. Soc. Am. J. 49, 127-130.

Slesak, R.A., Schoenholtz, S.H., Harrington, T.B., 2011. Soil carbon and nutrient pools in Douglas-fir plantations 5 years after manipulating biomass and competing vegetation in the Pacific northwest. For. Ecol. Manag. 262, 1722-1728.

Slesak, R.A., Harrington, T.B., D'Amato, A.W., 2016a. Invasive scotch broom alters soil chemical properties in Douglas-fir forests of the Pacific northwest, USA. Plant Soil 398, 281-289.

Slesak, R.A., Harrington, T.B., Peter, D.H., DeBruler, D.G., Schoenholtz, S.H., Strahm, B.D., 2016b. Effects of intensive management practices on 10-year Douglas-fir growth, soil nutrient pools, and vegetation communities in the Pacific northwest, USA. For. Ecol. Manag. 365, 22-33.

Smethurst, P.J., Nambiar, E.K.S., 1995. Changes in soil carbon and nitrogen during the establishment of a second crop of Pinus radiata. For. Ecol. Manag. 73, 145-155.

Kellogg soil survey laboratory methods manual. In: Soil Survey Staff, Burt and Soil Survey Staff (Eds.), Soil Survey Investigations Report No. 42, Version 5.0. R. U.S. Department of Agriculture, Natural Resources Conservation Service.

Soil Survey Staff, 2014b. Keys to Soil Taxonomy, 12th ed. USDA-Natural Resources Conservation Service, Washington, DC.

Soil Survey Staff, 2019. Natural Resources Conservation Service. Official Soil Series Descriptions United States Department of Agriculture Available online at. https:// soilseries.sc.egov.usda.gov/osdname.aspx, Accessed date: 30 January 2019.

Spears, J.D.H., Lajtha, K., Caldwell, B.A., Pennington, S.B., Vanderbilt, K., 2001. Species effects of Ceanothus velutinus versus Pseudotsuga menziesii, Douglas-fir, on soil phosphorus and nitrogen properties in the Oregon cascades. For. Ecol. Manag. 149, 205-216.

Tan, K.H., 1982. Principles of Soil Chemistry. Marcel Dekker, Inc, New York.

Taylor, M.D., 2000. Determination of Total phosphorus in soil using simple Kjeldahl digestion. Commun. Soil Sci. Plant Anal. 31 (15\&16), 2665-2670.

Trasar-Cepeda, M.C., Gil-Sotres, F., Guitian-Ojea, F., 1990. Relation between phosphorus fractions and development of soils from Galicia (NW Spain). Geoderma 47, 139-150.

Vitousek, P.M., Farrington, H., 1997. Nutrient limitation and soil development: experimental test of biogeochemical theory. Biogeochemistry 37, 63-75.

Vitousek, P.M., Matson, P.A., 1985. Disturbance, nitrogen availability, and nitrogen losses in an intensively managed loblolly pine plantation. Ecology 66, 1360-1376.

Vitousek, P.M., Porder, S., Houlton, B.Z., Chadwick, O.A., 2010. Terrestrial phosphorus limitation: mechanisms, implications, and nitrogen-phosphorus interactions. Ecol. Appl. 20 (1), 5-15.

Wada, K., 1989. Allophane and Imogolite. In: Dixon, J.B., Weed, S.B. (Eds.), Minerals in soil environment, $2^{\text {nd }}$ ed. Soil Sci. Am. Book Series No. 1 ASA and SSSA, Madison, WI, pp. 1057-1087.

Walker, T.W., Syers, J.K., 1976. The fate of phosphorus during pedogenesis. Geoderma $15,1-19$.

Wang, X., Lester, D.W., Guppy, C.N., Lockwood, P.V., Tang, C., 2007. Changes in phosphorus factions at various soils depths following long-term P fertilizer application on a Black Vertosol from south-eastern Queensland. Aust. J. Soil Res. 45, 524-532.

Wood, T., Bormann, F.H., Vogt, G.K., 1984. Phosphorus cycling in a northern hardwood forests: biological and chemical control. Science 223, 391-393.

Yang, X., Post, W.M., 2011. Phosphorus transformations as a function of pedogenesis: a synthesis of soil phosphorus data using Hedley fractionation method. Biogeosciences 8 (10), 2907-2916. 